\section{Dr Jekyll et Mr Histone : protéger ou tuer, la dualité des histones}

Lydie Viatte

\author{
Département endocrinologie, \\ métabolisme et cancer, Inserm U567, Université Paris \\ Descartes, \\ Faculté de médecine René Descartes, \\ CNRS, UMR-S 8104, Institut Cochin, \\ 24, rue du Faubourg Saint-Jacques, \\ 75014 Paris, France. \\ lydie.viatte@inserm.fr
}

> Les histones sont des partenaires indispensables de la molécule d'ADN : elles permettent sa compaction dans le noyau et contrôlent l'état d'ouverture de la chromatine. Mais ces protéines, au nombre de cinq décrites $(\mathrm{H} 1, \mathrm{H} 2 \mathrm{~A}$, $\mathrm{H} 2 \mathrm{~B}, \mathrm{H} 3$ et $\mathrm{H} 4$ ) ne sont pas cantonnées dans le noyau et peuvent être détectées dans le milieu extracellulaire et notamment dans la circulation sanguine. Un rôle antibactérien des histones circulantes avait été démontré dès 1958 [1]. L'origine de ces histones circulantes est encore peu connue ; elles pourraient provenir des polynucléaires neutrophiles qui, lors d'une nécrose particulière appelée NETosis, libèrent de I'ADN lié à des histones ainsi que d'autres protéines formant des pièges extracellulaires (ou NET, neutrophil extracellular traps) capables de détruire les bactéries comme nous l'avons déjà évoqué dans ces colonnes [2]. C'est en cherchant à comprendre le mécanisme par lequel la protéine $C$ recombinante activée (APC) exerçait son effet thérapeutique dans les cas de septicémie grave (associée à au moins deux défaillances viscérales) qu'une équipe de chercheurs a découvert un autre rôle des histones [3]. L'APC, dont l'utilisation est approuvée depuis 8 ans dans le sepsis, est une protéase aux propriétés anti-inflammatoires, cytoprotectrices et anticoagulantes [4]. Elle résulte du clivage de la protéine C par la thrombine fixée par la thrombomoduline. Son activité anticoagulante s'exerce via l'inactivation par clivage des facteurs Va et VIIla de la coagulation. Mais cette activité anticoagulante n'est pas nécessaire à l'effet protecteur de I'APC en cas de septicémie, et les chercheurs ont postulé l'implication d'autres protéines cibles de I'APC dans ce rôle thérapeutique. Ils ont ainsi identifié des formes clivées de $\mathrm{H} 4, \mathrm{H} 3$ et $\mathrm{H} 2 \mathrm{~A}$ en présence d'APC et ont observé que les histones intactes sont toxiques pour les cellules endothéliales in vitro. L'injection intraveineuse d'histones à des souris entraîne leur mort dans un tableau de défaillance proche de celui d'une septicémie. L'administration d'anticorps (Ac) neutralisant les histones améliore la survie de ces souris ayant reçu ces protéines, et I'APC, qui dégrade in vivo les histones et donc les inactive, a un effet comparable. Ces molécules, Ac ou APC, améliorent aussi la survie de souris en état de choc septique après infection bactérienne (Figure 1). Les

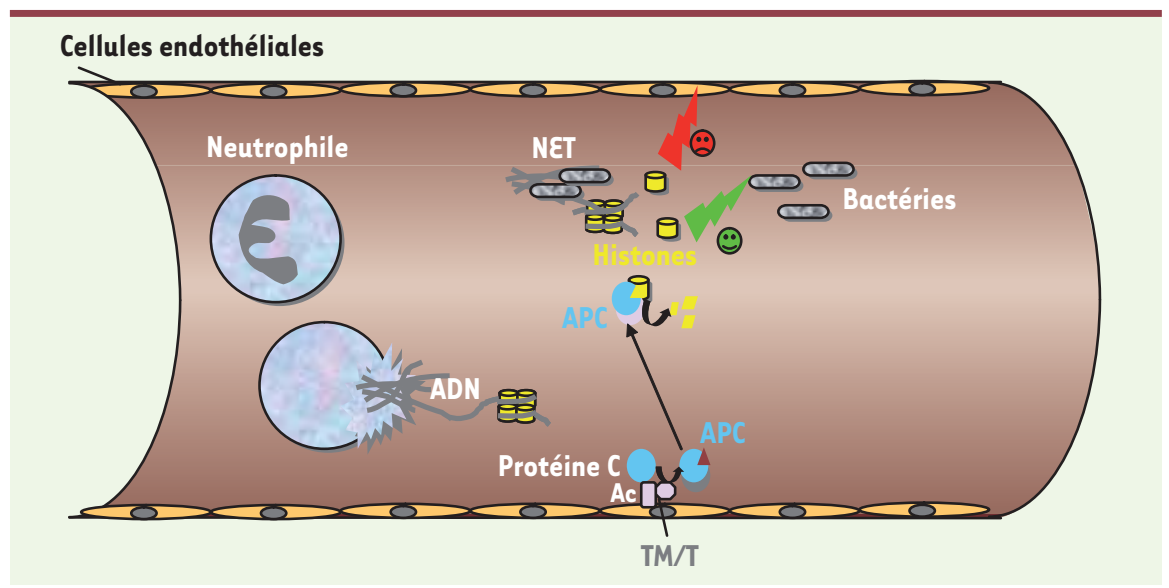

Ac antihistones pourraient ainsi représenter une alternative thérapeutique à I'APC qui, en raison de ses propriétés anticoagulantes, peut entraîner des saignements. Toutefois le revers de la médaille est que bloquer l'action antibactérienne des histones, bénéfique lors des septicémies, peut ne pas être dépourvu d'inconvénients. Morale de l'histoire : ne pas se fier au côté angélique des histones qu'on croyait uniquement bénéfiques par leur protection de I'ADN et leur rôle anti-bactérien. $\diamond$

Dr Jekyll and Mr Histone:

protect or kill, the duality of histones

\section{CONFLIT D'INTÉRÊTS}

L'auteur déclare n'avoir aucun conflit d'intérêts concernant les données publiées dans cet article.

\section{RÉFÉRENCES}

1. Hirsch JG. Bactericidal action of histone. J Exp Med 1958 ; $108: 925-44$

2. Gougerot-Pocidalo MA, દl Benna J, My-Chan Dang P, Elbim C. Quand les polynucléaires neutrophiles attrapent les agents pathogènes dans leurs filets Med Sci (Paris) 2007 ; $23: 464-5$.

3. Xu J, Zhang X, Pelayo R. et al. Extracellular histones are major mediators of death in sepsis. Nat Med 2009 ; 15: 1318-21.

4. Mosnier LO, Zlokovic BV, Griffin JH. The cytoprotective protein C pathway. Blood 2007 ; 109 : 3161-72.

Figure 1. Résumé de l'action des histones extracellulaires. Lorsqu'un polynucléaire neutrophile est lysé (à gauche), il libére de l'ADN (gris) couplé à des histones (jaune). Ces histones entières ont un double rôle : bénéfique car elles piègent des bactéries (filets NET), mais elles peuvent aussi attaquer et activer les cellules endothéliales, provoquant une défaillance viscérale. La protéine $C$, activée (APC) par l'action du couple thrombine (T)-thrombomoduline (TM) dégrade les histones et les inactive, prévenant les lésions endothéliales. Un anticorps anti-histones aurait le même effet. 